\title{
Creating and evaluating a global classroom to teach nursing research
}

\author{
Barbara Amendolia , Kathleen Fisher, Deanna Schaffer, Kathryn Howarth \\ College of Nursing and Health Professions, Drexel University, Philadelphia, United States
}

Received: October 11, 2015

Accepted: December 10, $2015 \quad$ Online Published: December 22, 2015

DOI: $10.5430 /$ jnep.v6n4p117

URL: http://dx.doi.org/10.5430/jnep.v6n4p117

\begin{abstract}
Background: The purpose of this educational innovation was to expose undergraduate nursing students to methods of research and evidence-based practice through dissemination at a research conference and interaction with nurse researchers.

Methods: Students from the United States attended an interdisciplinary research conference in Dublin Ireland that integrated the research process into their nursing education. In addition, they were exposed to a very different approach to nursing education through interaction within a global classroom.

Results: Following the experience, students expressed a greater understanding of the overall research process. Students were both surprised and impressed that bedside nurses could be actively engaged in research and could envision nursing research as a component of their scope of practice.

Conclusions: Infusion of research into pre-licensure programs remains a challenge for nursing faculty. International experiences and global classrooms can be a way to meet this challenge and raise enthusiasm about nursing research.
\end{abstract}

Key Words: Nursing education, Research, Global classroom

\section{INTRODUCTION}

Teaching senior level undergraduate nursing research can be a daunting task. Attention at this point in nursing programs is often focused on the future, including final exams, and impending employment, and many students see a limited role for research in their professional careers as Registered Nurses. It is not unusual for nursing research faculty to be asked: "Why is this important for me to learn?" and "Can you please just teach me a skill I will need and use as an RN?" The typical response to these questions includes an explanation about evidence based practice and Magnet hospitals, which seems to satisfy a few. Faculty also point out the contribution of nursing research to patient care, health policy and expanded nursing practice. ${ }^{[1]}$ Students are often surprised and discouraged when they learn that it can take up to 17 years for research to be translated into clinical practice. ${ }^{[2]}$ As a result, faculty continues to struggle to find ways of sparking interest in research for the undergraduate nursing student.

\section{NuRSing: A PRACTICE PROFESSION AND ACADEMIC DISCIPLINE}

Nursing as a practice profession has a long history, going back to the 1870s when the first US nursing school opened at Bellevue Hospital in New York City, based on Florence Nightingale's "training model" for nursing. ${ }^{[3]}$ Finding ways to include experiential learning of the research process is a challenge. Consideration of the nurse researcher role within

*Correspondence: Barbara Amendolia; Email: bja39@drexel.edu; Address: College of Nursing and Health Professions, Drexel University, Philadelphia, United States.

Published by Sciedu Press 
the practice of nursing is even more formidable. It is important to integrate experiential learning opportunities for students in order to broaden their practice focused thinking. Hence, our global classroom experience included attendance at an interdisciplinary research conference. During the planning phase of the experience, we were unaware that only one student had ever attended a nursing conference meeting, so it was exciting to be acculturating this group into the profession and the world of research.

Our discipline is about relational, creative, evolving practice that is informed by the evidence, with research as an integral ingredient to developing a knowledge base and supporting clinical practice and outcomes. ${ }^{[4]}$ Nursing has progressed from social science based studies to federally funded programs of research that translate cellular level and animal model experimentation to clinical nursing interventions that inform and support health care practice. ${ }^{[5]}$

One unique learning opportunity that was able to highlight the importance of nursing research involved two undergraduate students in their first year of training. ${ }^{[6]}$ The students were involved as team members on a federally funded $\mathrm{Na}$ tional Institute of Nursing Research study. Involved from the beginning of the project, they were exposed to the entire research process including multidisciplinary team meetings, research training, a genetics educational program and a worksite facilities tour. Following the research study experience, the two students expressed a much deeper understanding of the role of the nurse researcher and how this role could potentially impact and expand future options for them in the profession. ${ }^{[6]}$

\section{Critical thinking AND NURsing RE- SEARCH}

Nursing students are expected to learn critical thinking skills as required in developing as capable, knowledgeable and experienced professional care practitioners. ${ }^{[7]}$ Further, it is argued that educators need to teach critical thinking skills to prepare nurses to become leaders in the nursing profession. ${ }^{[8]}$ One early model for critical thinking identified five components, which included: specific knowledge base, experience, competencies, attitudes and standards. ${ }^{[9]}$ The American Nursing Association (ANA) has applied critical thinking to the nursing process, describing a reflective, deliberate and disciplined process. ${ }^{[7]}$

Researchers developed and revised a clinical critical thinking skills test with 20 graduates and college level nursing students, validating it with six expert nurses to assess critical thinking ability. ${ }^{[10]}$ Domains tested included: Analysis (e.g., ability to interpret and identify missing information; Recog- nizing inconsistencies in data); Inference (e.g., supporting conclusion with evidence, asking questions for recognition of problems, seeking information, and drawing valid conclusions); Evaluation (e.g., validating data, critique of research on evidence based nursing; presenting criteria on evidence, detecting one's biases); and Synthetic Thinking (e.g., finding safe, effective/efficient ways to implement care, exploring alternatives to a given problem, communicating clearly and transforming knowledge). While they were testing clinical critical thinking ability, and some of the items within the domains are clearly "clinical", many items are similar to those used by nurse researchers.

An international panel of nursing experts from Brazil, Canada, England, Iceland, Japan, Korea, Netherlands, Thailand, and 23 states in the US, created a consensus definition of critical thinking in nursing. Skills such as analyzing, applying standards, discriminating, information seeking, and logical reasoning, predicting and transforming knowledge were included in the definition. Consensus panel findings, they argue, can be utilized by practitioners, educators and researchers in advancing our understanding of the crucial role of critical thinking. ${ }^{[11]}$ We posit that while critical thinking skills are viewed as necessary in the delivery of care; these skills are also required of the nurse researcher. ${ }^{[8]}$ In an effort to entice students to consider nursing research as a future career focus in nursing we planned and embarked upon an international experience and a global initiative Students traveled along with professors to an interdisciplinary healthcare research conference, experiencing firsthand the research process by engaging with researchers, simultaneously with a global experience.

\section{BACKGROUND ON THE GLOBAL CLASS- ROOM}

The traditional methods of teaching lecture style are slowly beginning to decrease in popularity, shifting towards more integrated learning, global experiences, and the uses of technology. With the rising demand for nurses, the needs to have a more developmental learning curriculum that instructs as well as brings the students other experiences increases as well. $^{[12]}$ Technology implementation, specifically videoconferencing, has played a significant role due to the fact that it is widely renowned for enhancing the nursing education experience. Videoconferencing has been used thus far for clinical case discussions as well as educational learning. [13] These conferences can be from other countries, providing a different cultural learning experience as well as enhancing the educational experience. ${ }^{[12]}$ A majority of the reviews for videoconference teaching have been positive, indicating that pedagogy is an important aspect to a student's satisfaction 
of distance learning, feeling engaged throughout the entire experience. ${ }^{[13]}$ Videoconferencing provides an innovative curricular activity challenging the students thus engaging them. ${ }^{[12]}$

Videoconferencing is not the only type of technology that is being implemented into curriculum. Prerecorded lecture videos either recorded by the professor himself/herself or sharing existing recordings with students is another way technology is entering the educational experience. ${ }^{[14]}$ Providing pre-existing recordings can cause an issue with teaching or subject nuances, but it could provide a method of explanation that a student may better relate to. There are many positive reviews by the students themselves for this type of teaching method, describing it as a rewarding, yet difficult journey to learn the material. ${ }^{[14]}$

Social media is probably the most controversial of the emerging technologies that faculty are adapting. Social media can have mixed results depending on the student that is using it and if he/she is determined or dedicated enough to not allow himself/herself to get distracted by social media. ${ }^{[15]}$ Professors are using the internet as a mean of connection, collaboration, and innovation to create a new learning experience for students in the form of social media. Blogs have been a common channel for this type of connection and expression. ${ }^{[15]}$ Social media's controversy is a reason that it has not caught on so quickly. There are many who believe social media should be utilized in education for the way it connects with students making learning more personal, and there are those who disagree saying that it puts too much of the responsibility in the students' hands. ${ }^{[15]}$ Professors can begin focusing on teaching students to self-regulate their learning, promoting them to use their social media websites to further learn and continue their studies. ${ }^{[15]}$ Recorded videos can be applied to a global classroom setting like videoconferencing or posted on social media websites. By targeting the material towards student learning and cultural experiences, these same positive responses may be evoked.

\section{Administrative perspective}

There were multiple factors to consider in the organization and structure of this global classroom initiative, including the confusing factor of global classroom versus international experience. When first discussed, faculty members were planning what was thought to be an international experience in which a small group of students in the United States would interact with students from Ireland. What the experience turned out to be was vastly different and significantly more complicated. The classroom turned into a hybrid teaching model with both a global classroom aspect where the entire class interacted via social media with the international stu-

Published by Sciedu Press dents as well as an international experience for the students who were able to attend the research conference in Ireland.

\section{Challenges}

At the start of the term, the social networking (Facebook) page was established by faculty and senior level nursing students enrolled in the undergraduate research course. Senior level nursing students in the United States were required to join. The social network assignment included 2 posts each from all students in the US addressing questions related to their education and the health care delivery differences between the two countries. Posts were to be backed by current nursing literature and cited utilizing APA format. One student refused to join the group page as well as any online interaction because she did not have a Facebook page as a result of a prior stalking incident. This student was permitted to complete the social media assignments individually and submit via email directly to faculty.

Additional challenges identified included locating individual student Facebook posts as this form of social media allows users to choose screen names which may be different than those on record with the University roster and subsequently in the gradebook. This was not anticipated by faculty teaching the course and proved very time consuming and frustrating for both student and faculty. Also, some posts on Facebook were difficult to find as a result of the "news feed" changing thus not always coinciding with the actual order of the posts. Finally, engaging the students from Ireland proved challenging as many were not able to join the group page until well into the term due to communication issues. Students were able to interact before the conference in Ireland where they met in person.

\section{SYNOPSIS OF EXPERIENCE}

A total of 7 students and 2 faculty members traveled to Dublin Ireland for a 2-day interdisciplinary research conference and student colloquium. Students were immediately immersed in the Irish culture and learned of the history of the Kilmainham jail and of the many political prisoners who were tortured and executed there. They also got some first glimpses of Dublin Castle, Trinity College and St Patrick's Cathedral and enjoyed a traditional Irish meal. A planned meeting with five pediatric nurse researchers from the Children's University Hospital on Temple Street was followed by an extensive tour of many of the units in the hospital. Students had reviewed research studies conducted at the hospital prior to this meeting and learned of their graduate programs like the Graduate Diploma Pediatric in Critical Care Nursing. This is one of two core programs and one of Ireland's best. As part of their education, which is equivalent to a 
Master's degree in the US, students are required to complete a research project. The real life experience of these nurse researchers engaged students and was followed by the tour of many of the units in the hospital. Students were fascinated to see the differences in this Children's hospital compared to the United States as many of them had completed clinical rotations at two academic specialty hospitals; the Children's Hospital of Philadelphia (CHOP) and St Christopher's Children's Hospital.

It was during the 15th Healthcare Interdisciplinary Research Conference and Student Colloquium that students were able to see nursing research presented and discussed and also to listen to some very interesting keynote speakers. Students also met with Irish students and faculty from Trinity College and were treated to a private tour of the University, a tour of the Book of Kells and a reception in the Long Library. It was at this point that students interacted with nursing students from Trinity College who they had been communicating with via social media (Facebook) throughout the quarter in a Global Classroom.

Cultural experiences continued after the conference as students and faculty toured the Guinness Factory, Jamison Distillery, Dublin Castle and Temple Bar. Students also experienced a horse and carriage ride to a Hooley Dinner/Dance at Arlington where they enjoyed traditional Irish singing and River dancing along with a traditional Irish dinner. The last day of the experience involved a full day excursion which included travel to Galway city and a visit to the Cliffs of Moher, including a drive along the Wild Atlantic Way.

On-line and electronic connections with nursing students who didn't make the trip were planned. We had hoped to use everyone's smart phones to record all meetings and cultural events as snap-chats, face-time and short videos on smart phones as available to us. This proved challenging as faceto-face interaction with the Irish students was limited to one meeting at a location outside of Trinity and faculty were not invited to attend. There was no video to upload and share on Facebook with the students in the US and this limited their experience as compared to the students who traveled to Ireland. We were able to upload pictures of the cultural experiences and or the visits to Temple Street Children's Hospital and Trinity College.

\section{Future plans}

Feedback received from the students included recommendations for extending the length and scope of the international experience. Anecdotally, they reported understanding the role of the nurse researcher, and were quite impressed that practicing "clinical" nurses were so engaged in research as they observed awhile touring Temple Street Hospital. They lobbied that future trips would include tours of community hospitals as well as specialty ones. In general, nursing students do not have the opportunity to explore study abroad programs. According to students, this unique experience was beneficial in that, they were able to continue their clinical courses and exam schedules while taking advantage of this learning opportunity. Future directions include a more extensive cultural experience to include different regions including Belfast in Northern Ireland and an extended stay in Galway. While in Belfast plans include a black taxi tour to explore the regions history as well as interaction with faculty and students from universities.

\section{Conclusion}

Raising enthusiasm about nursing research can be discouraging. Nurse educators continue to brainstorm in an effort to meet the challenge of teaching nursing research in ways that engage and excite students. Immersion in real life nursing research experiences, whether here or abroad, is something that we need to consider if the goal is for nursing students to identify research skills and appraisal of evidence as one of their core competencies in their education and future professional practice. International experiences and Global Classrooms are one innovative way to meet this challenge. Development of similar experiences can help faculty convey to nursing students that the possibilities for them as registered nurses are endless.

\section{CONFLiCtS OF INTEREST Disclosure}

The authors declare that there is no conflict of interest.

\section{REFERENCES}

[1] American Association of Colleges of Nursing (AACN). AACN Position Statement on Nursing Research. 2014. Available from: http://www.aacn.nche.edu/publications/positio n/NsgResearch.pdf

[2] Morris ZC, Wooding S, Grant J. The answer is 17 years, what is 120 the question: Understanding time lags in translational research. Journal of the Royal Society of Medicine. 2011; 104(12): 510520. PMid:22179294 http://dx.doi.org/10.1258/jrsm. 2011 .110180

[3] Wikipedia. Bellevue Hospital Center. 2015. Available from: https: //en.wikipedia.org/wiki/Bellevue_Hospital_Center 
[4] O'Shea. The State of the discipline of nursing: science, technology and culture have stirred rapid change. 2001. Available from: http: //emory.edu/ACAD_EXCHANGE/2001/octnov/oshea.html

[5] NINR. (nd) Research and funding. Available from: http://www.ni $\mathrm{nr} / \mathrm{nih}$.gov/researchfunding\#.VfCWI-ID11I

[6] Tingen M, Burnett A, Murchison R, et al. The Importance of Nursing Research. Journal of Nursing Education. 2009; 48(3): 167-170. http://dx.doi.org/10.3928/01484834-20090301-10

[7] Foundation for Critical Thinking. Nursing and Health Care. 2015. Available from: http://www.criticalthinking.org/pages/n ursing-and-health-care/801

[8] Banning M. Nursing Research: Perspectives on Critical Thinking. British Journal of Nursing. 2006; 8(15): 458-461. PMid:16723953 http://dx.doi.org/10.12968/bjon.2006.15.8.20966

[9] Kataoka-Yahiro M, Saylor C. A Critical Thinking Model for Nursing Judgment. The Journal of Nursing Education. 1994; 33(8): 351-356. PMid:7799094

[10] You SY, Kim NC. Validation of a clinical critical thinking skills test in nursing. Journal of Korean Academy of Nursing. 2014; 44(2): 129138. PMid:24859118 http://dx. doi .org/10.4040/jkan. 2014 .44 .2 .129

[11] Scheffer BK, Rubenfeld MG. A consensus statement on critical thinking in nursing. The Journal of Nursing Education. 2000; 39(8): 352-359. PMid:11103973
[12] Murray TA. Innovations in Nursing Education: The State of the Art. Journal of Nursing Regulation. 2013; 3(4): 25-31. Available from: http://www. journalof nursingregulation.com/con tent/QHL225K6P6864464 http://dx.doi.org/10.1016/S21 55-8256 (15) 30183-6

[13] Zalon ML, Meehan TC. Merging time zones: Promoting international communication through videoconferencing. Nurse Education in Practice. 2005; 5(3): 180-186. Available from: http://www.sciencedirect.com/science/article/ pii/S1471595304001179 PMid:19038197 http://dx.doi.org $/ 10.1016 / j . n e p r .2004 .10 .005$

[14] Schwartz TA. Flipping the Statistics Classroom in Nursing Education. Journal of Nursing Education. 2014; 53(4): 199-206. Available from: http://search.proquest.com/docview/155529 2201?pq- PMid:24654591 http://dx.doi.org/10.3928/014 84834-20140325-02

[15] Dabbagh N, Kitsantas A. Personal Learning Environments, social media, and self-regulated learning: A natural formula for connecting formal and informal learning. The Internet for Higher Education. 2012; 15(1): 3-8. Available from: http://www.sciencedirect.com/ science/article/pii/S1096751611000467 http://dx.doi .org/10.1016/j.iheduc. 2011.06.002 